\title{
Imigraçâo e identidades nacionais na América Latina: o elo esquecido
}

Nicola Foote \& Michael Goebel (orgs.). Immigration and national identities in Latin America. Gainesville, University Press of Florida, 2014. 356 páginas.

\section{Márcio de Oliveira}

Os estudos imigratórios sempre mantiveram uma relação distante (por vezes ambígua) com a história dos nacionalismos e com o tema das identidades nacionais. Não surpreende, portanto, que o tema da identidade nacional tenha sido pouco associado ao da imigração nos países latino-americanos, com as conhecidas exceçôes negativas que ocorreram em momentos históricos e contextos políticos nativistas, eugênicos e racialmente xenófobos. Com base nessa constatação, os historiadores Nicola Foote e Michael Goebel, a primeira norte-americana e professora na Universidade da Flórida e o segundo, alemão, professor na Universidade de Berlin, organizaram em livro um quadro geral dessa situação, analisando países tão diferentes quanto o México e o Uruguai, além de Argentina e Brasil, com especial e inovadora atenção à região do Caribe.

O objetivo do livro é compreender de que modo as migraçōes europeia e asiática impactaram de forma cruzada e transversal, ou seja, dos dois lados do Atlântico e entre os diferentes países de destino, os discursos e movimentos nacionalistas, as imagens e projetos de identidade nacional em países latino-americanos, entre 1850 e 1950 . A simples proposição da equação "imigração-identidade nacional" para a América Latina já é algo inovador. A larga periodização escolhida indica que o impacto das migrações é mais atual do que se imagina. Com efeito, nos círculos intelectuais e políticos latino-americanos, o tema da identidade nacional esteve sempre às voltas (por vezes às turras) com a questão indígena, com o tema da escravidão e com a questão racial, e só muito lateralmente, com a questão imigrante. Trata-se de fato do elo menos trabalhado, mas a partir do qual a discussão sobre a relação entre diversidade étnico-racial e identidade nacional/Estado-nação na América Latina ganha uma nova dimensão. O livro não tem por foco a discussão sobre o papel que tiveram os imigrantes na ocupação de espaços nacio- 
nais parcamente povoados, no aumento da produção agrícola e na expansão industrial, embora apresente em detalhes o fato de que as representaçôes em torno deles oscilaram das imagens positivas de embranquecimento da população e desenvolvimento àquelas negativas dos preconceitos e das ameaças à soberania nacional. O objetivo de fundo é mostrar a relação entre a chegada das populações imigrantes europeias e asiáticas, os processos de consolidação nacional e os movimentos nacionalistas. A imigração é apresentada como o grande movimento demográfico e intelectual, no interior do qual as ideias sobre nacionalismo viajaram tanto quanto foram (in) conscientemente carregadas e constantemente reenviadas pelos imigrantes a seus países de origem, neles causando impacto ainda pouco aquilatado. Dito de outro modo, na coletânea em questão, a grande imigração é pensada como um processo histórico que inspira definições de nação tanto nos países latino-americanos por onde circularam quanto nos países europeus, asiáticos ou árabes de onde partiram. Os fluxos demográficos impactaram, retroativamente, antigos Estados que não haviam se consolidado, colidindo ainda com impérios em colapso, ao mesmo tempo construindo e colocando em xeque nacionalismos diversos, e isso durante toda a primeira metade do século XX.

Segundo os autores, o livro tem por origem as discussões realizadas no âmbito de sua formação doutoral na University College London, sob a direção da historiadora Nicola Miller. Ganhou concretude através do painel sobre migrações e identidades nacionais na América Latina, ${ }^{1}$ organizado durante o encontro anual da British Society for Latin American Studies, realizado em Bristol (Inglaterra) em 2010. O objetivo fixado naquele momento era seguir pistas e preencher lacunas abertas, entre outros, pelos livros clássicos de Walter $\mathrm{Nu}$ gent, Crossings: the great transatlantic migrations, 1870-1914 (1995), e de Samuel Baily e Eduardo José Miguez, Mass migration to modern Latin America (2003). Podemos completar a lista acrescentando que os textos apresentados dialogam também com os livros de Carl Solberg, Immigration and nationalism: Argentine and Chili, 1890-1914 (1970), e de Jeffrey Lesser, Immigration, ethnicity and national identity in Brazil, 1808 to the present (2013). ${ }^{2}$
Como era de se esperar em tamanho esforço panorâmico, as escolhas recaíram nos principais países, Argentina e Brasil. Trouxeram, porém, novidades em relação ao Uruguai, ao México e aos países do Caribe, o que, paradoxalmente, nos faz questionar o significado de "América Latina" como unidade analítica. Em relação aos imigrantes, os capítulos analisam os grupos ainda hoje mais conhecidos (italianos, espanhóis e alemães). Apesar dos acréscimos importantes de Jeffrey Lesser, em direção aos imigrantes árabes, chineses e judeus, e de Buchenau, em direção aos chineses instalados no México, reproduzem-se na coletânea as tradicionais lacunas de estudos sobre russos, ucranianos e poloneses, especialmente importantes no sul do Brasil e na Argentina. Contudo, como novidade, os organizadores ampliaram a clássica periodização das grandes migraçôes, 1870-1930, para o período compreendido entre 1850 e 1950. Goebel relembra que a imigração para América Latina declinou após os anos de 1930, assim como declinou sua parcela proporcional em relação à população total. Além de ter decrescido, essa população miscigenou-se de forma bem mais ampla (diferentemente do que ocorreu nos Estados Unidos) e deixou de ser estatisticamente contada nos censos populacionais. Mas, questiona o autor, ainda que os imigrantes tenham se integrado de maneira mais forte na América Latina (e tenham tido aí mais sucesso econômico também), pouco dessas experiências exitosas foi transformado em novos quadros analíticos, o que justifica a nova periodização escolhida.

A leitura do livro pode ser feita de maneira livre, sem necessidade de respeitar a sequência de capítulos proposta. No entanto, a Introdução e a Conclusão apresentam análises inovadoras que se complementam e, por isso, convido o leitor a familiarizar-se com as questôes ali discutidas, para que a leitura dos capítulos torne-se mais proveitosa. Assinada individualmente por Goebel, a Introdução anuncia claramente o partido histórico-metodológico escolhido: trata-se de comparar, de maneira cruzada, situaçóes específicas, pensando o impacto de grupos de imigrantes sobre as formaçōes nacionais. 
Dois grandes temas entrelaçam-se no texto: a história social dos migrantes e a história dos nacionalismos na América Latina. Em relação ao primeiro, a maior parte dos estudos sobre imigração tem por foco a dimensão étnica ou nacional dos grupos imigrantes, o passaporte emitido pelo país de origem sendo o critério de classificação. Nesses estudos, os migrantes são analisados com base em uma classificação jurídica: migrantes de um país (europeu ou asiático) para outro (latino-americano). Eles são, portanto, associados a naçóes. Isso ocorreu com os irlandeses transformados em ingleses na Argentina e com os poloneses transformados em alemães no Brasil. A confusão das nacionalidades (mesmo para aqueles que haviam partido de uma nação soberana) amalgamou, sem eliminar, muitas das diferenças sociais e culturais existentes entre os grupos migrantes. Era de se supor que tais diferenças ressurgissem nas sociedades de destino e, de fato, foi o que aconteceu. Em consequência, primeiro, as sociedades receptoras adotariam as distinçôes nativas, reproduzindo com cores próprias situações de conflito transportadas; segundo, os primeiros estudos latino-americanos sobre os imigrantes não apenas se serviram e reforçaram algumas das representações importadas, mas também se limitaram a examinar a trajetória dos diversos grupos com base apenas na equação "grupo individual de migrantes-nação receptora", ignorando os conflitos transnacionais preexistentes.

Goebel afirma ainda que a ausência de perspectiva comparativa entre imigrantes em diversos países colocou em plano secundário as migrações que ocorreram após a chegada ao continente latino-americano. Em consequência, muito dos movimentos nacionalistas das décadas de 1910 e 1920, em países como o Brasil ou a Argentina, pode ser considerado uma consequência não apenas do importante contingente de imigrantes, mas também de suas trajetórias cruzadas naqueles espaços. Em uma palavra, os sentimentos nacionais latino-americanos foram fruto também de experiências partilhadas em vários destinos. A partir disso, Goebel mostra que conflitos e sentimentos nacionalistas também migraram e/ou foram gestados pelos processos de migração, para então retornarem e atuarem nos países de origem. Isso parece ter sido o caso de Garibaldi e Anita, na Itália, e de chineses remigrados do Peru e de Cuba que ativamente participaram da "Revolução de 1911" na China. Em conclusão, o autor mostra que no século XIX as definições de nacional e de migrantes eram mais fluidas do que hoje imaginamos, mesmo nos continentes europeu e asiático.

A imigração para América Latina declinou drasticamente a partir dos anos de 1930. Esse fato acabou por restringir o objeto de estudo aos historiadores e ao quadro teórico de então: os estudos da chamada Escola de Chicago e seu par conceitual aculturação/assimilação. Não obstante, nos Estados Unidos, onde a imigração não cessou, os estudos renovaram-se teórica e empiricamente, interessando outras disciplinas. Contudo, mesmo lá, as análises teriam insistido na relação entre imigrantes e sociedade acolhedora, destacando ainda temas como a assimilação e a ascensão social dos grupos e deixando à margem os debates sobre identidade nacional.

Esse último ponto diz respeito ao quadro conceitual discutido pelos autores e ao processo histórico da imigração na América Latina. Goebel afirma que a oposição entre "assimilação"3 e "pluralismo" é referência nos estudos sobre a história da imigração na América Latina, mas não sobre o estudo da história dos nacionalismos. Assim, os estudiosos da imigração afastaram-se dos debates dos historiadores sobre os nacionalismos. Nos Estados Unidos, os sociólogos é que mantiveram o interesse pelo tema da imigração. Na Inglaterra e mesmo na França, os estudos sobre nacionalismo ficaram a cargo de historiadores, antropólogos e cientistas políticos, para os quais, regra geral, as migrações mostravam fluxos que aportavam em nações já constituídas e estáveis. Em resumo, o resgate da relação entre imigração e nacionalismo é o ponto forte do livro.

Feita essa introdução, passemos em revista os conteúdos específicos de cada capítulo, agrupados pelos organizadores em duas grandes partes, a saber, "Espaços da migração" e "Pessoas migrantes", no interior das quais prevalece sempre a perspectiva comparativa em relação à formação dos Estados-nação latino-americanos. Na primeira parte, trata-se de acompanhar e comparar os diversos grupos de imigrantes em uma única realidade geográfica, definida em termos nacionais; na segunda, trata- 
-se de acompanhar e comparar o "mesmo" grupo em distintas realidades nacionais. Quais foram os impactos desses movimentos populacionais nas formaçôes das identidades dos migrantes, nas consciências nacionais e nas próprias nações, em ambos os lados do Atlântico?

Abrindo a primeira parte, o capítulo "Migrantes, nações e impérios em transição: reivindicações nativas no Grande Caribe, 1850-1930" analisa os processos de entradas e saídas de imigrantes na região do Caribe, ocorridos entre 1850 e 1930 . Putnam utiliza aqui o conceito de entangled history para dar conta das consequências cruzadas provocadas pelos fluxos de imigrantes dos países europeus à América Latina e também pelas movimentaçôes internas. História entrelaçada, emaranhada, interdependente, ou, como sugiro, entrelaçamento histórico, ${ }^{4}$ em qualquer uma dessas traduçôes, a tese é de que a história do Caribe não pode ser separada em partes nacionais estanques. O capítulo termina questionando quais tipos de países os anos de 1930 viram surgir na região. Como os fluxos migratórios e os atos discriminatórios não tinham sido tão contínuos, o local de nascimento não era mais suficiente para definir o pertencimento ou a nacionalidade.

O segundo capítulo analisa a relação entre imigrantes e nação no México. Durante o governo de Álvaro Obregón Salido (1922-1924), o então secretário de educação, José Vasconcelos, cunhou a expressão "raça cósmica", acreditando que os imigrantes contribuiriam para a criação de uma nova raça, mestiça e superior. A escolha do caso mexicano surpreende positivamente, porque o país nunca se percebeu como uma nação de imigrantes, mas sim de espanhóis e indígenas. $\mathrm{O}$ autor mostra, contudo, que os imigrantes europeus que se instalaram no México recusaram a integração e desenvolveram estratégias de autoexclusão. Era o paradoxo entre uma elite xenófila e um sentimento popular xenófobo. Diante desses fatos, como estabelecer uma relação entre imigrantes e nação? À diferença de suas congêneres sul-americanas, na sociedade mexicana, a assimilação dos estrangeiros europeus não se tornou regra.

O capítulo "Imigração, identidade e nacionalismo na Argentina, 1850-1950" analisa os debates em torno da definição do "ser argentino" após a chegada de milhôes de europeus, parte deles pro- testantes ou judeus. À diferença do que ocorreu no México ou no Brasil, na Argentina, a discussão sobre o futuro da nação e sobre sua identidade nacional lidou apenas lateralmente com a herança indígena e africana. Assim, a clivagem ideológica em torno da nacionalidade não opôs o passado indígena e africano às elites hispânicas colonizadoras, mas sim o discurso dessas últimas às práticas sociais e culturais dos grupos de imigrantes, em especial italianos, que pouco a pouco marcaram o horizonte cultural, social e econômico do país.

O capítulo "Nação e migração: falantes de alemão e imigrantes japoneses no Brasil, 1850-1945" propõe uma análise das conclusões a que chegaram o sociólogo Arthur Hehl Neiva e o major Aristóteles da Lima Câmara, ambos defensores da política de assimilação do governo Vargas (1930-1945) no Brasil, após a viagem que realizaram a diversas antigas colônias de imigrantes, localizadas nas regiōes Sul e Sudeste. No relatório, ambos apontam a dificuldade de assimilação demonstrada pelos descendentes de imigrantes, em especial de poloneses, alemães e japoneses. Servindo-se do testemunho de um líder religioso alemão que visitou algumas dessas comunidades, questiona-se o teor daquelas conclusões. Aparentemente, os colonos (descendentes de) imigrantes não eram assim tão resistentes à assimilação, antes o contrário. Colocada a questão nesses termos, o autor discute como as noções de nação e de imigração foram apresentadas no debate brasileiro.

A segunda parte do livro, "Pessoas migrantes", traz inicialmente o capítulo "Pátrias escolhidas: etnicidade, pertencimentos e identidades entre judeus latino-americanos". Parte-se aqui do pressuposto que tanto nos relatos quanto nos estudos sobre imigrantes na América Latina, a questão étnica é excessivamente dimensionada. Com o estudo dos judeus no Brasil e na Argentina, os autores pretendem ultrapassar o viés comunitário ou étnico, afirmando hipoteticamente que "ser judeu" na América Latina é uma identificação pessoal (uma estratégia dos atores, diria Bourdieu) que seria até mesmo transportada para outros países, quando de uma eventual remigração.

$\mathrm{O}$ capítulo seguinte tem por tema as minorias alemãs na América Latina durante a Primeira Guerra Mundial. O ponto central é: o que teria ocorrido 
durante os anos da chamada Grande Guerra? Apesar do grande número de associações, escolas e igrejas apoiadas por esse impulso vindo de fora, o autor afirma que a homogênea germanidade das comunidades imigrantes havia sido política e culturalmente construída. Com efeito, a diversidade no seio delas era a característica mais marcante, embora os laços religiosos, tanto católicos quanto protestantes, tenham efetivamente se reforçado no início do século.

O capítulo "A busca da legitimidade: imigrantes chineses e a construção da nação latino-americana" parte da constatação comum às elites latino-americanas e caribenhas: chineses são trabalhadores eficientes, embora prejudiciais ao bem-estar físico e moral da nação. Comparando países - Cuba, Peru e México - onde a imigração chinesa foi particularmente importante, analisa-se como a retórica da construção da nação revela a tensa relação entre discursos, atos discriminatórios e políticas das sociedades acolhedoras, de um lado, e atitudes dos próprios imigrantes em defesa de suas reivindicaçóes de cidadania e de pertencimento, de outro. Como, em todos esses países, a preferência por imigrantes europeus brancos permaneceu a regra, os processos de assimilação e de miscigenação dos imigrantes chineses acabaram por ocorrer com os estratos mais baixos das populaçôes locais, em especial de origem africana e indígena.

O capítulo "Migração caribenha britânica e a racialização dos nacionalismos latino-americanos" analisa os discursos nacionalistas latino-americanos sobre imigração no contexto da migração provinda do caribe britânico. A população imigrante caribenha, de origem africana, era justamente o oposto do ideal de branqueamento procurado pelos países vizinhos. Como então as elites latinas lidaram com a necessidade de migrantes, quando esses eram afro-americanos? Se alguém ainda tinha dúvida sobre o fato de o negro imigrante nunca ter feito parte do grupo dos desejáveis na América Latina, agora não tem mais.

O capítulo "Fascismo italiano e nacionalismos diaspóricos na Argentina, Brasil e Uruguai" inscreve-se no interior do grande debate sobre a diversidade das trajetórias dos Italiani nel mondo (Blanc-Chaléard et al., 2007). Na história da imigração, os imigrantes italianos são considerados aqueles que, em tese, mais criaram enclaves étnicos e urbanos (Little italies), mas, paradoxalmente, aqueles que mais se adaptaram e transformaram (e também mais fizeram prosperar) as sociedades que os receberam. No caso em tela, examina-se a dispersão, não de italianos em carne e osso, mas de uma ideologia o fascismo -, analisando-a em relação à diáspora dos nacionalismos, exatamente quando, na virada do século XX, a cultura italiana foi mais forte nos três países em tela, Argentina, Brasil e Uruguai. Os imigrantes italianos, instalando-se em grande número nas capitais dos países do Prata, mesclaram-se às elites e ao nacionalismo local, afastando-se assim do fascismo da pátria longínqua. Muito diferente foi o comportamento dos imigrantes italianos no Brasil paulista. Não estando concentrados na capital do país e não se envolvendo com as questões nacionais, mostraram-se mais étnicos e mais próximos do nacionalismo fascista italiano.

O último capítulo do livro, "Nacionalismos entre colônias árabe-falantes na América Latina", aborda a formação de nacionalismos em alguns dos Estados - Síria, Líbano e Israel - que mais sofreram influências de acontecimentos mundiais, desde a emergência e o declínio dos mandados francês e britânico na região, passando pela Primeira Guerra Mundial e pela decadência dos três grandes impérios, em particular o Império Otomano. Em síntese, os emigrantes, uma vez nos países de destino, participaram de forma variada no duplo processo de construção e busca de identidades nacionais dos dois lados do Atlântico.

$\mathrm{Na}$ "conclusão", assinada individualmente por Nicola Foote, o objetivo do livro - fazer dialogar o estudo da migração e a história dos nacionalismos é retomado. O desenvolvimento dos Estados-nação latino-americanos está, afirma a autora, "inextricavelmente entrelaçado às correntes migratórias globais" (p. 281). Daí, o desejo de escrever a história das naçóes latino-americanas a partir de suas fronteiras e do considerável aumento de suas populaçôes, conferindo a essa obra uma unidade rara no gênero das coletâneas.

O conjunto dos capítulos reatualiza diversos debates, que convém ressaltar:

1. A questão da supostamente exitosa assimilação na América Latina em contraste com as identidades hifenizadas comuns nos Estados Unidos. 
2. A diáspora dos nacionalismos. $\mathrm{Na}$ verdade, os imigrantes desempenharam um papel nos processos nacionais nos dois lados do Atlântico, ou seja, trazendo nacionalismos tanto quanto ajudando ou impedindo sua criação.

3. A questão da raça e da etnia. Com efeito, o tema da imigração não vem sendo associado à discussão sobre a questão racial na América Latina.

4. A questão do gênero. Pouco estudadas, as mulheres migrantes foram excluídas das definições legais e, indiretamente, acabaram por desafiar tanto os estereótipos sobre a suposta incapacidade de deixar seus lares quanto aqueles que as ligavam à prostituição.

Como dissemos no início, ao contrário do que ocorre com as heranças indígena e negra, a questão imigrante ainda é o elo menos presente nos estudos sobre identidade nacional nos círculos latino-americanos. O presente livro, com análises precisas e originais, em muito contribuirá para corrigir isso.

\section{Notas}

1 Por ocasião da 46 Conferência anual da British Society for Latin America Studies, Goebel coordenou um painel intitulado "Migration and national indentities in Latin America since Independence".

2 Em termos teóricos, o livro retoma pontos estabelecidos por DeWind e Portes (2004).

3 A respeito da história desse conceito, ver o excelente artigo de Green (2006).

$4 \mathrm{O}$ conceito de entangled history é frequentemente associado à expressão histoire croisée. Essa última, por vezes alçada à condição de método, pretende ultrapassar a contextualização histórica tradicional e o método comparativo tout court.

\section{BIBLIOGRAFIA}

BAILY, Samuel L. \& MÍGUEZ, Eduardo J. (ed.). (2003), Mass migration to modern Latin America. Wilmington, Scholary Resources.

BLANC-CHALEARD, Marie-Claude et al. (2007), Les petites italies dans le monde. Rennes, PUR.
DÉLOYE, Yves. (1997), Sociologie politique du historique. Paris, La Découverte.

DEWIND, Josh \& PORTES, Alejandro. (2004), "A Cross-Atlantic dialogue: the progress of research and theory in the study of international migration". International Migration Review, 38 (3): 828-851.

GREEN, Nancy. (2006), "Time and study of assimilation”. Rethinking History, 10 (2): 238-258.

LESSER, Jeffrey. (2013), Immigrants, ethnicity and national identity in Brazil, 1808 to the present. Cambridge, Cambridge Press University.

NUGENT, Walter. (1995), Crossings: the great transatlantic migrations. Indiana, Indiana University Press.

SOLBERG, Carl. (1970), Immigration and nationalism: Argentine and Chili, 1890-1914. Austin, Institut of Latin American Studies/Texas Press University.

\section{MÁRCIO DE OLIVEIRA é professor titular de sociologia na Universidade Federal do Paraná. E-mail: marciodeoliveira@ufpr.br.}

DOI: http//dx.doi.org/10.17666/3190177-182/2016 